\title{
Assessment of Peripheral Neuropathy in Patients With Rheumatoid Arthritis Who Complain of Neurologic Symptoms
}

\author{
Mi Kyung Sim, $\mathrm{MD}^{1}$, Dae-Yul Kim, $\mathrm{MD}, \mathrm{PhD}^{1}$, Jisun Yoon, $\mathrm{MD}^{1}$, \\ Dae Hwan Park, $\mathrm{MD}^{1}$, Yong-Gil Kim, $\mathrm{MD}, \mathrm{PhD}^{2}$
}

\begin{abstract}
${ }^{1}$ Department of Rehabilitation Medicine, Asan Medical Center, University of Ulsan College of Medicine, Seoul; ${ }^{2}$ Division of Rheumatology, Department of Internal Medicine, Asan Medical Center, University of Ulsan College of Medicine, Seoul, Korea
\end{abstract}

Objective To assess the prevalence of peripheral neuropathy in patients with rheumatoid arthritis (RA) having neuropathic symptoms, and to investigate the relationship between electrophysiological findings of peripheral neuropathy and clinical findings of RA.

Methods Patients with a clinical diagnosis of RA and who had tingling or burning sensation in any extremity were electrophysiologically examined for evidence of peripheral neuropathy. Study parameters, including age, gender, laboratory parameters, duration of RA, and medication, were recorded. The symptoms and signs of neuropathy were quantified with the neuropathy symptom score, and the functional statuses of these patients were assessed.

Results Out of a total of 30 RA patients, 10 (33\%) had peripheral neuropathy: 2 had bilateral carpal tunnel syndrome (CTS), 5 had unilateral CTS, 1 had sensory polyneuropathy, and 2 had motor-sensory polyneuropathy. The mean ages of the patients with and without peripheral neuropathy were 69.4 and 56.5 years, respectively $(\mathrm{p}<0.05)$. A significant relationship was found between peripheral neuropathy and anti-cyclic citrullinated peptide (anti-CCP) antibody. However, no relationship was found between peripheral neuropathy and the type of medication, RA duration, the patients' functional status, neuropathic symptoms, erythrocyte sedimentation rate, and C-reactive protein values.

Conclusion Neuropathic symptoms are common in RA patients, and it is difficult to distinguish peripheral neuropathy symptoms from those of arthritis. Patients with RA, particularly elderly patients and anti-CCP antibody positive patients who complain of neuropathic symptoms should undergo electrophysiological examination.

Keywords Rheumatoid arthritis, Peripheral neuropathy, Anti-cyclic citrullinated peptide

Received August 27, 2013; Accepted October 21, 2013

Corresponding author: Dae-Yul Kim

Department of Rehabilitation Medicine, Asan Medical Center, University of Ulsan College of Medicine, 88 Olympic-ro 43-gil, Songpa-gu, Seoul 138736, Korea

Tel: +82-2-3010-3800, Fax: +82-2-3010-6964, E-mail: kysmart@amc.seoul.kr

(c) This is an open-access article distributed under the terms of the Creative Commons Attribution Non-Commercial License (http://creativecommons.org/ licenses/by-nc/3.0) which permits unrestricted noncommercial use, distribution, and reproduction in any medium, provided the original work is properly cited. Copyright $\odot 2014$ by Korean Academy of Rehabilitation Medicine 


\section{INTRODUCTION}

Rheumatoid arthritis (RA) is a systemic inflammatory disease that mainly affects the joints [1]. Although the main manifestations involve the joints, previous studies have reported that extra-articular manifestations occur in $10 \%-20 \%$ of RA patients and that these symptoms correlate with increased mortality [2]. Clinical neuropathy occurs in $0.5 \%$ to $85 \%$ of RA patients [3-6], and presents in the form of mononeuritis multiplex, sensorimotor neuropathy, and entrapment neuropathy [5]. Clinical neuropathy may present with a wide variety of symptoms, such as pain, paresthesias, and muscle weakness. These symptoms may mimic and overlap those of arthritis, and it is difficult to distinguish peripheral neuropathy symptoms from arthritis symptoms.

The various causes of peripheral neuropathy in RA include nerve entrapment, drug toxicity, vasculitis, and rarely amyloidosis $[7,8]$. A few studies also suggest that the development of RA can be attributed to an autoimmune phenomenon $[9,10]$. However, few reports have explored the relationship between peripheral neuropathy and clinical findings in RA patients. The aim of this study was to electrophysiologically evaluate peripheral neuropathy in RA patients with neurologic symptoms, and to demonstrate the relationships between peripheral neuropathy and demographic, clinical, and laboratory findings.

\section{MATERIALS AND METHODS}

\section{Patients}

Patients with a clinical diagnosis of RA who had tingling or burning sensation in any extremity were enrolled in this study. All of the patients met the American College of Rheumatology criteria for RA [11]. Exclusion criteria were 1) patients with systemic diseases or conditions that are associated with neuropathy (i.e., diabetes mellitus, hypothyroidism, amyloidosis, alcohol intake, liver failure, chronic renal failure treated by hemodialysis, or pregnancy), 2) patients who underwent orthopedic surgery, and 3) patients with neurologic disorders. The recorded parameters included age, gender, duration of RA, laboratory test results, medications, neuropathic symptoms, and functional status. Laboratory tests included erythrocyte sedimentation rate (ESR), C-reactive protein (CRP), rheumatoid factor (RF), and anti-cyclic citrullinated peptide (anti-CCP) antibody.

\section{Methods}

\section{Neuropathic symptom measurement}

Neuropathic symptoms and signs were quantified with the neuropathy symptom scale (NSS). The NSS is a fivequestion multiple-choice self-report inventory that is used for measuring the severity of neuropathic symptoms and signs. The NSS has a maximum score of 9, with a higher score indicating more severe neuropathic symptoms [12]. The functional status of patients with RA was classified as class I-IV according to the revised criteria for the classification of the functional status in RA. A higher class reflects a poorer functional status [13].

\section{Electrophysiological study}

Electrophysiological studies were performed using the Medelec-Synergy EMG instrument (Oxford Instrument Co., Surrey, UK). The skin temperature was kept between $31^{\circ} \mathrm{C}$ and $32^{\circ} \mathrm{C}$. Median, ulnar, peroneal, and posterior tibial motor nerve conduction studies (NCSs), including F-waves, were performed unilaterally on the symptomatic side. Median, ulnar, superficial peroneal, and sural sensory NCSs were performed unilaterally on the symptomatic side. The latency of the $\mathrm{H}$-wave was measured bilaterally. Motor NCSs were performed using the bellytendon method. Sensory nerve conduction was studied antidromically. All amplitudes were determined based on the base-to-peak value; the peak latency and onset latency were measured for sensory nerve action potential (SNAP) and compound motor action potential (CMAP), respectively. The conduction velocity of each nerve was measured. Findings were compared with the reference values that are used in our center as described in Table 1.

A bilateral study of three extremities was conducted if the NCS showed abnormal findings. Polyneuropathy was diagnosed when at least three abnormal parameters were present. If the median CMAP latency was greater than $4.2 \mathrm{~ms}$ or the median SNAP was greater than $3.6 \mathrm{~ms}$, we used the 'mid-palm' technique to diagnose carpal tunnel syndrome (CTS). In this technique, the median nerve was stimulated at the wrist and the median SNAP was recorded in digit 3 at a $7-\mathrm{cm}$ distance (palm). The median nerve was then stimulated at the palm at a $14-\mathrm{cm}$ distance (wrist). Presence of CTS was considered when 
Table 1. Reference values for the nerve conduction study that were used in the present study

\begin{tabular}{lccc}
\hline \multicolumn{1}{c}{ Nerve } & $\begin{array}{c}\text { Latency } \\
(\mathbf{m s})\end{array}$ & $\begin{array}{c}\text { Ampli- } \\
\text { tude }^{\mathbf{b})}\end{array}$ & $\begin{array}{c}\text { Velocity } \\
(\mathbf{m} / \mathbf{s})\end{array}$ \\
\hline Motor & & & \\
Median & $<4.2$ & $>5.0$ & $>50$ \\
Ulnar & $<4.2$ & $>5.0$ & $>50$ \\
Deep peroneal & $<6.2$ & $>2.0$ & $>40$ \\
Posterior tibial & $<5.0$ & $>5.0$ & $>40$ \\
F-wave & & & \\
Median & $<30$ & - & - \\
Ulnar & $<30$ & - & - \\
Deep peroneal & $<50$ & - & - \\
Posterior tibial & $<50$ & - & - \\
Sensory & & & \\
Median & $<3.6$ & $>20$ & - \\
\hline Ulnar & $<3.6$ & $>10$ & - \\
Superficial peroneal & $<4.2$ & $>5$ & - \\
\hline Suralm & $<3.9$ & $>10$ & - \\
H-reflex & $<32$ & - & - \\
\hline
\end{tabular}

a) Peak latencies of all sensory nerves, onset latencies of all motor nerves.

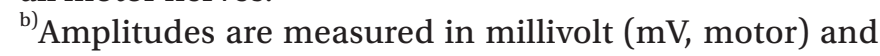
in microvolt $(\mu \mathrm{V}$, sensory).

the ratio of palm to wrist latency was lower than $50 \%$. All of the patients gave informed consent, and the study was approved by the ethics committee of our university. Patients were then divided into two groups according to the presence or absence of peripheral neuropathy. The clinical and laboratory findings were compared between the two groups.

\section{Statistical analysis}

Statistical analyses were performed with SPSS 13.0 for Windows (SPSS Inc., Chicago, IL, USA). For comparison between the two groups, a Mann-Whitney U test or t-test was used for continuous variables and a Fisher exact test was used for categorical variables. The variables were analyzed with univariate logistic regression analysis to determine their effects on polyneuropathic involvement. Odds ratios and $95 \%$ confidence intervals (CIs) were calculated for each factor. In addition, multivariable regression analyses were performed to assess the independent association between peripheral neuropathy and each factor. All of the variables with $\mathrm{p}$-value $<0.2$ by univari- ate analysis were selected for the multivariable logistic regression analysis. A p-value of $<0.05$ was considered statistically significant.

\section{RESULTS}

A total of 30 RA patients ( 26 women and 4 men) were enrolled in this study. Of these, 10 patients showed peripheral neuropathy in the electrophysiological study: 2 had bilateral CTS, 5 had unilateral CTS, 1 had sensory polyneuropathy, and 2 had sensorimotor polyneuropathy. Two patients had peripheral neuropathy of the lower limbs, 1 patient had neuropathy of both upper and lower limbs, and 7 patients had isolated upper limb involvement. The mean ages of the patients with and without peripheral neuropathy were 69.4 and 56.5 years, respectively $(\mathrm{p}<0.05)$. The duration of the disease was 96.8 months in patients without peripheral neuropathy and 54.1 months in patients with peripheral neuropathy, respectively. All of the patients without peripheral neuropathy were in functional stage class I, whereas some of the patients with peripheral neuropathy were in class II and class IV. However, there was no statistically significant difference in the RA duration and functional stage between the two groups. Among the 20 patients without peripheral neuropathy, 13 patients $(65.0 \%)$ showed a positive RF and 8 patients (40.0\%) showed a positive antiCCP antibody. In contrast, among the 10 patients with peripheral neuropathy, all of the patients were positive for RF, and 8 patients (80.0\%) were positive for anti-CCP antibody. Patients with peripheral neuropathy were thus more likely to have a positive serological marker for RA than those without peripheral neuropathy; however, this difference was not statistically significant using the Fisher exact test (Table 2).

We found that anti-CCP antibody was significantly associated with an increased risk of polyneuropathy using a univariate logistic regression model (relative risk [RR], 6.00; 95\% CI, 1.00-35.91). Age was also significantly associated with presence of peripheral neuropathy in univariate logistic regression analysis (RR, 1.083; 95\% CI, 1.00-1.17). Multiple regression analysis demonstrated that peripheral neuropathy in RA patients was independently increased by age (RR, 1.12; 95\% CI, 1.02-1.13) and anti-CCP antibody (RR, 14.27; 95\% CI, 1.37-148.26) (Table 3 ). Age of patients did not show a difference according to 
Table 2. Characteristics of the patients in the two groups

\begin{tabular}{|c|c|c|c|}
\hline Characteristic & $\begin{array}{l}\text { Peripheral neuropathy (-) } \\
(\mathbf{n = 2 0 )}\end{array}$ & $\begin{array}{c}\text { Peripheral neuropathy }(+) \\
(\mathbf{n}=10)\end{array}$ & p-value \\
\hline Age (yr) & $56.5 \pm 13.3$ & $69.4 \pm 9.3$ & $0.028^{*}$ \\
\hline Gender (male:female) & $2: 18$ & $2: 8$ & 0.584 \\
\hline Duration of RA (mo) & $96.8 \pm 128.4$ & $54.1 \pm 69.1$ & 0.843 \\
\hline Functional stage & & & 0.103 \\
\hline Class I & 20 & 8 & \\
\hline Class II & 0 & 1 & \\
\hline Class III & 0 & 0 & \\
\hline Class IV & 0 & 1 & \\
\hline Rheumatoid factor (+) & 13 & 10 & 0.064 \\
\hline Anti-CCP antibody (+) & 8 & 8 & 0.058 \\
\hline ESR $(\mathrm{mm} / \mathrm{hr})$ & $24.2 \pm 18.8$ & $37.2 \pm 22.7$ & 0.108 \\
\hline $\mathrm{CRP}(\mathrm{mg} / \mathrm{dL})$ & $0.5 \pm 0.7$ & $1.7 \pm 3.9$ & 0.286 \\
\hline NSS score & $3.8 \pm 2.7$ & $3.7 \pm 2.4$ & 0.964 \\
\hline \multicolumn{4}{|l|}{ Medication } \\
\hline DMARDs (+) & 16 & 9 & 0.064 \\
\hline Steroid (+) & 13 & 6 & 1.000 \\
\hline Anti-TNF (+) & 0 & 0 & 1.000 \\
\hline
\end{tabular}

Values are presented as mean \pm standard deviation or numbers.

RA, rheumatoid arthritis; anti-CCP, anti-cyclic citrullinated peptide; ESR, erythrocyte sedimentation rate; CRP, Creactive protein; NSS, neuropathy symptom scale; DMARDs, disease modifying anti-rheumatic drugs; anti-TNF, antitumor necrosis factor.

${ }^{*} \mathrm{p}<0.05$ by Fisher exact test for categorical variables or by $\mathrm{t}$-test or Mann-Whitney $\mathrm{U}$ test for continuous variables.

the presence or absence of anti-CCP antibody. Age of patients who were positive for anti-CCP antibody and negative for anti-CCP antibody was $59.2 \pm 12.4$ and $61.1 \pm 14.1$ years, respectively. When we compared the odds ratio of anti-CCP antibody for peripheral neuropathy according to age, odds ratio of anti-CCP antibody was higher in the old age group (Table 4). No significant association was found between peripheral neuropathy and gender, NSS, functional stage, ESR, CRP, type of medication, and RF.

\section{DISCUSSION}

The prevalence and electrophysiological findings of peripheral neuropathy and their relationship with demographic, clinical, and laboratory findings have not been clearly demonstrated in the literature. The prevalence of peripheral neuropathy and its related factors vary among previous studies, as shown in Table 5 [5,6,14-16]. Furthermore, it is difficult to compare studies examining peripheral neuropathy in RA because the inclusion crite- ria and neuropathy assessment methods varied between previous reports. In our current study, we reported a frequency of peripheral neuropathy, including entrapment neuropathy of $33.3 \%$ in RA patients, which appears to be lower than that in previous studies with a large series of patients, which included entrapment neuropathy as peripheral neuropathy. The frequency of peripheral neuropathy in this study was higher than the frequency of idiopathic polyneuropathy of $\mathbf{8 \%}$, which was reported previously in a population-based epidemiological study [17].

Although we included RA patients with neurological symptoms in our current study, the prevalence of neuropathy in the electrophysiological study was lower than that in other studies. In addition, there was no relationship between the NSS and the presence of peripheral neuropathy, which may be because the NSS consists of questions that focus on positive symptoms, such as burning and tingling, which are subjectively reported by the patients. Furthermore neuropathic symptoms mimic the 
Table 3. Variables associated with peripheral neuropathy in RA

\begin{tabular}{|c|c|c|c|c|c|c|}
\hline \multirow{2}{*}{ Variable } & \multicolumn{3}{|c|}{ Univariate analysis } & \multicolumn{3}{|c|}{ Multivariate analysis } \\
\hline & OR & 95\% CI & p-value & OR & 95\% CI & p-value \\
\hline Age & 1.083 & $1.00-1.17$ & $0.040^{a)}$ & 1.12 & & $0.019^{b)}$ \\
\hline Gender & & & 2.250 & - & & \\
\hline Male & 2.250 & $2.25-2.25$ & & & & \\
\hline Female & 1.000 & & & & & \\
\hline Anti-CCP antibody & & & $\mathbf{0 . 0 5 0}^{\mathrm{a})}$ & & & $\mathbf{0 . 0 2 6}^{\mathrm{b})}$ \\
\hline$(+)$ & 6.000 & $1.00-35.91$ & & 14.27 & $1.37-148.26$ & \\
\hline$(-)$ & 1.000 & & & 1.000 & & \\
\hline ESR & 1.032 & $0.99-1.07$ & 0.117 & - & & \\
\hline CRP & 1.339 & $0.74-2.42$ & 0.335 & - & & \\
\hline NSS score & 0.984 & $0.72-1.34$ & 0.917 & - & & \\
\hline DMARDs & & & 0.497 & - & & \\
\hline Yes & 2.250 & $0.22-23.32$ & & & & \\
\hline No & 1.000 & & & & & \\
\hline Steroids & & & 0.789 & - & & \\
\hline Yes & 0.808 & $0.17-3.86$ & & & & \\
\hline No & 1.000 & & & & & \\
\hline
\end{tabular}

RA, rheumatoid arthritis; OR, odds ratio; CI, confidence interval; anti-CCP, anti-cyclic citrullinated peptide; ESR, erythrocyte sedimentation rate; CRP, C-reactive protein; NSS, neuropathy symptom scale; DMARDs, disease modifying anti-rheumatic drugs.

${ }^{a)} \mathrm{p}<0.05$ by univariate logistic regression, ${ }^{\text {b) }} \mathrm{p}<0.05$ by multivariate logistic regression.

Table 4. Effects of anti-CCP antibody on peripheral neuropathy according to age

\begin{tabular}{ccccc}
\hline Age & Anti-CCP antibody & OR & 95\% CI & p-value* \\
\hline$\leq 60(\mathrm{n}=17)$ & $(+)$ & 3.500 & $0.284-43.161$ & 0.328 \\
& $(-)$ & 1 & - & - \\
$>60(\mathrm{n}=13)$ & $(+)$ & 12.500 & $0.839-186.299$ & 0.067 \\
& $(-)$ & 1 & - & - \\
\hline
\end{tabular}

Anti-CCP, anti-cyclic citrullinated peptide; OR, odds ratio; CI, confidence interval.

${ }^{*} \mathrm{p}<0.05$ by multivariable logistic regression.

symptoms of arthritis. Because of these reasons, symptoms of patients might show a poor correlation with results of electrophysiological studies. A poor correlation between the clinical and electrophysiological parameters in our study is in accordance with the results of some studies [6,14], although not all of the studies [18].

In our present study, we did not find a significant association between peripheral neuropathy and gender, RA duration, functional status of patients, RF, ESR, CRP, and type of medication. We found that RA patients with peripheral neuropathy were older than RA patients without peripheral neuropathy. Age is a known risk factor for polyneuropathy [19], and RA patients with peripheral neuropathy in our electrophysiological study showed similar results. However, the prevalence of peripheral neuropathy in patients with RA in this study was higher than that of peripheral neuropathy in patients without the underlying disease.

The important finding of our current study was that patients who were positive for anti-CCP antibody showed an increased risk of peripheral neuropathy. The anti-CCP antibody has become a focus of attention for diagnosis and it is a marker of severe RA [20]. A recent study reported that anti-CCP antibody is associated with human 
Table 5. Comparison between electrophysiological patterns of peripheral neuropathy and associated factors reported in the present and previous studies

\begin{tabular}{|c|c|c|c|c|c|c|c|}
\hline \multirow{2}{*}{ Study } & \multirow{2}{*}{$\begin{array}{c}\text { No. of } \\
\text { patients }\end{array}$} & \multicolumn{5}{|c|}{ Type of peripheral neuropathy } & \multirow{2}{*}{$\begin{array}{l}\text { Factors associated with } \\
\text { peripheral neuropathy }\end{array}$} \\
\hline & & SM & $\mathbf{S}$ & $\mathbf{M}$ & MM & CTS & \\
\hline Fleming et al. [15] & 102 & 0 & 15 & 3 & 0 & 52 & * \\
\hline Agarwal et al. [6] & 108 & 25 & 28 & 0 & 7 & 11 & $\begin{array}{l}\text { Absence of DTR, } \\
\text { Presence of vasculitis }\end{array}$ \\
\hline Lanzillo et al. [14] & 40 & 26 & 0 & 0 & 0 & 3 & * \\
\hline Nadkar et al. [5] & 31 & 6 & 0 & 4 & 4 & 1 & * \\
\hline Bayrak et al. [16] & 60 & 8 & 2 & 0 & 0 & * & $\begin{array}{l}\text { Duration of RA, NSS, NDS, } \\
\text { DAS } 28\end{array}$ \\
\hline Present study & 30 & 2 & 1 & 0 & 0 & 7 & Age, anti-CCP antibody \\
\hline
\end{tabular}

SM, sensorimotor; S, sensory; M, motor; MM, mononeuritis multiplex; CTS, carpal tunnel syndrome; DTR, deep tendon reflex; RA, rheumatoid arthritis; NSS, neuropathy symptom score; NDS, neuropathy disability score; DAS 28, 28-joint disease activity score; anti-CCP, anti-cyclic citrullinated peptide.

*Not investigated.

leukocyte antigen (HLA) class II RA-related susceptibility alleles and severe disease manifestations [21]. Although some authors have observed a tendency for a positive association between anti-CCP antibody titer and extraarticular manifestations in RA, there is no data on the effects of anti-CCP antibody on the development of peripheral neuropathy [22-24]. Our current study is the first study to investigate the relationship between anti-CCP antibody and the development of peripheral neuropathy in RA patients. According to our results, RA patients who had anti-CCP antibodies have about a 14-fold increased risk of peripheral neuropathy. Also, the effect of anti-CCP antibody on peripheral neuropathy seems to increase with age.

Our study was limited by its small sample size and cross-sectional design. In addition, we were unable to conduct an electrophysiological study for the same duration from symptom onset. Moreover, we were unable to determine a definite cause of peripheral neuropathy and CTS in this study; whether it was as a result of a direct nerve injury due to joint deformity or it was an independent disease. Further longitudinal studies in a large population are needed.

It is difficult to distinguish the symptoms of peripheral neuropathy from those of arthritis, and the subjective symptoms of patients do not correlate with electrophysiological results. Hence, electrophysiological studies should be performed in patients with RA, particular in older patients and anti-CCP antibody positive patients.

\section{CONFLICT OF INTEREST}

No potential conflict of interest relevant to this article was reported.

\section{REFERENCES}

1. Sakini RA, Abdul-Zehra IK, Al-Nimer MS. Neuropathic manifestations in rheumatoid arthritis: a clinical and electrophysiological assessment in a small sample of Iraqi patients. Ann Saudi Med 2005;25:2479.

2. Turesson C, O'Fallon WM, Crowson CS, Gabriel SE, Matteson EL. Occurrence of extraarticular disease manifestations is associated with excess mortality in a community based cohort of patients with rheumatoid arthritis. J Rheumatol 2002;29:62-7.

3. Johnson RL, Smyth CJ, Holt GW, Lubchenco A, Valentine E. Steroid therapy and vascular lesions in rheumatoid arthritis. Arthritis Rheum 1959;2:224-9.

4. Good AE, Christopher RP, Koepke GH, Bender LF, Tarter ME. Peripheral neuropathy associated with rheumatoid arthritis: a clinical and electrodiagnostic study of 70 consecutive rheumatoid arthritis patients. Ann Intern Med 1965;63:87-99.

5. Nadkar MY, Agarwal R, Samant RS, Chhugani SJ, Idgunji SS, Iyer S, et al. Neuropathy in rheumatoid arthritis. J Assoc Physicians India 2001;49:217-20.

6. Agarwal V, Singh R, Wiclaf, Chauhan S, Tahlan A, 
Ahuja CK, et al. A clinical, electrophysiological, and pathological study of neuropathy in rheumatoid arthritis. Clin Rheumatol 2008;27:841-4.

7. Golding DN. Rheumatoid neuropathy. Br Med J 1971; 2:169.

8. Pouget J. Vascular neuropathies. Rev Prat 2000;50:74952.

9. Salih AM, Nixon NB, Gagan RM, Heath P, Hawkins $\mathrm{CP}$, Dawes PT, et al. Anti-ganglioside antibodies in patients with rheumatoid arthritis complicated by peripheral neuropathy. Br J Rheumatol 1996;35:725-31.

10. El M, Ashour S, Moustafa H, Ahmed I. Altered levels of soluble adhesion molecules in patients with rheumatoid arthritis complicated by peripheral neuropathy. J Rheumatol 2002;29:57-61.

11. Arnett FC, Edworthy SM, Bloch DA, McShane DJ, Fries JF, Cooper NS, et al. The American Rheumatism Association 1987 revised criteria for the classification of rheumatoid arthritis. Arthritis Rheum 1988;31:31524.

12. Dyck PJ, Sherman WR, Hallcher LM, Service FJ, O'Brien PC, Grina LA, et al. Human diabetic endoneurial sorbitol, fructose, and myo-inositol related to sural nerve morphometry. Ann Neurol 1980;8:590-6.

13. Aletaha D, Neogi T, Silman AJ, Funovits J, Felson DT, Bingham CO 3rd, et al. 2010 Rheumatoid arthritis classification criteria: an American College of Rheumatology/European League Against Rheumatism collaborative initiative. Arthritis Rheum 2010;62:2569-81.

14. Lanzillo B, Pappone N, Crisci C, di Girolamo C, Massini R, Caruso G. Subclinical peripheral nerve involvement in patients with rheumatoid arthritis. Arthritis Rheum 1998;41:1196-202.

15. Fleming A, Dodman S, Crown JM, Corbett M. Extraarticular features in early rheumatoid disease. Br Med J 1976;1:1241-3.

16. Bayrak AO, Durmus D, Durmaz Y, Demir I, Canturk F, Onar MK. Electrophysiological assessment of polyneuropathic involvement in rheumatoid arthritis: relationships among demographic, clinical and laboratory findings. Neurol Res 2010;32:711-4.
17. Beghi E, Monticelli ML. Chronic symmetric symptomatic polyneuropathy in the elderly: a field screening investigation of risk factors for polyneuropathy in two Italian communities. Italian General Practitioner Study Group (IGPST). J Clin Epidemiol 1998;51:697702.

18. Weller RO, Bruckner FE, Chamberlain MA. Rheumatoid neuropathy: a histological and electrophysiological study. J Neurol Neurosurg Psychiatry 1970;33:592604.

19. Mold JW, Vesely SK, Keyl BA, Schenk JB, Roberts M. The prevalence, predictors, and consequences of peripheral sensory neuropathy in older patients. J Am Board Fam Pract 2004;17:309-18.

20. Kroot EJ, de Jong BA, van Leeuwen MA, Swinkels H, van den Hoogen FH, van't Hof M, et al. The prognostic value of anti-cyclic citrullinated peptide antibody in patients with recent-onset rheumatoid arthritis. Arthritis Rheum 2000;43:1831-5.

21. van Gaalen FA, van Aken J, Huizinga TW, Schreuder GM, Breedveld FC, Zanelli E, et al. Association between HLA class II genes and autoantibodies to cyclic citrullinated peptides (CCPs) influences the severity of rheumatoid arthritis. Arthritis Rheum 2004;50:211321.

22. Ceccato F, Roverano S, Barrionuevo A, Rillo O, Paira S. The role of anticyclic citrullinated peptide antibodies in the differential diagnosis of elderly-onset rheumatoid arthritis and polymyalgia rheumatica. Clin Rheumatol 2006;25:854-7.

23. Turesson C, Jacobsson LT, Sturfelt G, Matteson EL, Mathsson L, Ronnelid J. Rheumatoid factor and antibodies to cyclic citrullinated peptides are associated with severe extra-articular manifestations in rheumatoid arthritis. Ann Rheum Dis 2007;66:59-64.

24. Kim SK, Park SH, Shin IH, Choe JY. Anti-cyclic citrullinated peptide antibody, smoking, alcohol consumption, and disease duration as risk factors for extraarticular manifestations in Korean patients with rheumatoid arthritis. J Rheumatol 2008;35:995-1001. 